Original Article

\title{
Effects of jaw opening exercise on aspiration in stroke patients with dysphagia: a pilot study
}

\author{
Dong-Hwan OH ${ }^{1)}$, Jung-HeE Won ${ }^{2)}$, Young-A KIM ${ }^{2)}$, Won-Jin KIM ${ }^{3)^{*}}$ \\ 1) Department of Occupational Therapy, KyungDong University, Republic of Korea \\ 2) Department of Rehabilitation Science, Graduate School of Inje University, Republic of Korea \\ 3) Department of Occupational Therapy, Kosin University: 194 Wachi-ro, Yeongdo-gu, Busan, \\ Republic of Korea
}

\begin{abstract}
Purpose] The purpose of this study was to investigate the effect of jaw opening exercise (JOE) on aspiration in patients with dysphagia after stroke. [Subjects and Methods] Three subjects were recruited. Isometric and isotonic JOE were performed using a rubber ball, 5 days a week for 4 weeks. Aspiration was evaluated using the penetration-a spiration scale (PAS) based on a videofluoroscopic swallowing study. [Results] All subjects showed a score reduction of at least 1 point and a maximum reduction of 2 points in the PAS in the liquid type. [Conclusion] This study confirmed that JOE can be used to reduce aspiration in patients with dysphagia after stroke. Key words: Aspiration, Dysphagia, Stroke
\end{abstract}

(This article was submitted Jul. 11, 2017, and was accepted Jul. 13, 2017)

\section{INTRODUCTION}

Jaw opening exercise (JOE) has recently been reported to be used as a remedial treatment for patients with dysphagia. JOE is a simple mouth opening exercise, but if resistance is applied in the direction opposite to that of mouth opening, the exercise activates the suprahyoid muscles (digastric, geniohyoid and mylohyoid muscles) ${ }^{1}$. Activation of the suprahyoid muscles is clinically important because of the potential for improving swallowing function in patients with dysphagia. Contraction of the suprahyoid muscles pulls the larynx upwards during swallowing to protect the airway and open the upper esophageal sphincter ${ }^{2}$. There is little evidence that JOE has been used in patients with dysphagia after stroke. The purpose of this study was to investigate the effect of JOE on swallowing function in patients with dysphagia after stroke.

\section{SUBJECTS AND METHODS}

We recruited 3 subjects with dysphagia after stroke. These subjects met the following inclusion criteria: diagnosis with dysphagia after stroke confirmed by a videofluoroscopic swallowing study, onset $<12$ months prior, no significant cognitive problems (Mini-Mental Status Examination score $>20$ ), able to perform mouth opening without any physical assistance. Subjects were excluded if they presented with trigeminal neuropathy, significant malocclusion and facial asymmetry, severe communication difficulties associated with dementia or aphasia, neck pain or neck surgery, or presence of a tracheostomy tube. Ethical approval was obtained from the Inje University Institutional Review Board before conducting the experiment (INJE 2017-01-009-003).

All subjects performed JOE using a rubber ball (circumference: $38 \mathrm{~cm}$ ) while seated in a chair. Subjects performed both isometric and isotonic variations of the JOE. In the isometric JOE, the subjects were asked to attempt to open their mouth against an external force for 60 seconds. They repeated the hold three times. In the isotonic JOE, the subject performed 30

*Corresponding author. Won-Jin Kim (E-mail: 114012@kosin.ac.kr)

(C2017 The Society of Physical Therapy Science. Published by IPEC Inc.

(c) (1) $\odot$ This is an open-access article distributed under the terms of the Creative Commons Attribution Non-Commercial No Deriva-

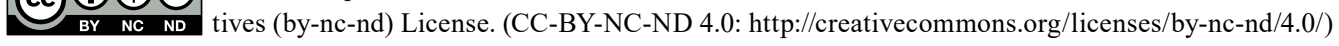


consecutive repetitions of mouth opening against the resistance of a rubber ball. The JOE were performed 5 days a week for 4 weeks. All subjects received conventional dysphagia treatment (CDT) in addition to the JOE. CDT includes oral facial muscle massage, palatal bowing stimulation, laryngeal movement, and tongue exercises. CDT was performed for 30 minutes, 5 times per week for 4 weeks. The penetration-aspiration scale (PAS) based on a videofluoroscopic swallowing study was used to evaluate the outcome of JOE. The PAS is an 8-point scale where a higher score indicates a greater degree of aspiration ${ }^{3}$.

\section{RESULTS}

After 4 weeks, Subject 1's PAS score decreased from 7 to 5 points with liquid type. Subject 2's score decreased from 6 to 4 points with liquid type. Subject 3's score decreased from 7 to 6 points with liquid type.

\section{DISCUSSION}

This study investigated the effect of JOE on aspiration in subjects with dysphagia after stroke. Three subjects were treated for 4 weeks. All subjects demonstrated a decrease in aspiration. JOE is known to activate the suprahyoid muscles ${ }^{1)}$. These muscles pull the larynx forward and upward. This movement causes the epiglottis to close, which has a direct effect on airway protection $^{2,4)}$. The upward movement of the larynx also affects the opening of the esophagus ${ }^{5)}$. If there is difficulty opening the upper esophageal sphincter, there is a greater risk of aspiration. Therefore, training of the suprahyoid muscles is important for the reduction of aspiration. This study confirms that JOE can be effective in reducing aspiration in dysphagia patients after stroke. This study has some limitations. First, the number of subjects was too small. Second, because we evaluated only aspiration, we did not study the other factors determining swallowing. Finally, the long-term effect of JOE could not be determined as the patients were not followed up.

\section{REFERENCES}

1) Wada S, Tohara H, Iida T, et al.: Jaw-opening exercise for insufficient opening of upper esophageal sphincter. Arch Phys Med Rehabil, 2012, 93: 1995-1999. [Medline] [CrossRef]

2) Park JS, Oh DH, Hwang NK, et al.: Effects of neuromuscular electrical stimulation combined with effortful swallowing on post-stroke oropharyngeal dysphagia: a randomised controlled trial. J Oral Rehabil, 2016, 43: 426-434. [Medline] [CrossRef]

3) Rosenbek JC, Robbins JA, Roecker EB, et al.: A penetration-aspiration scale. Dysphagia, 1996, 11: 93-98. [Medline] [CrossRef]

4) Paik NJ, Kim SJ, Lee HJ, et al.: Movement of the hyoid bone and the epiglottis during swallowing in patients with dysphagia from different etiologies. J ElectromyogrKinesiol, 2008, 18: 329-335. [Medline] [CrossRef]

5) Park JS, Hwang NK, Oh DH, et al.: Effect of head lift exercise on kinematic motion of the hyolaryngeal complex and aspiration in patients with dysphagic stroke. J Oral Rehabil, 2017, 44: 385-391. [Medline] [CrossRef] 